\title{
An Integrated Management System for Quality, Health and Safety, and Environment: A Case Study
}

\author{
Rui Ding ${ }^{1}$, Jintao $\mathrm{Xu}^{1}$, Yang Sui ${ }^{1,2, *}$ \\ ${ }^{1}$ School of Nuclear Science and Technology, University of South China, Hengyang, China \\ ${ }^{2}$ Fujian Fuqing Nuclear Power Co., Ltd, Fuzhou, China \\ Email address: \\ sydr1170@163.com (Rui Ding),xjt002729@163.com (Jintao Xu), suiyang@usc.edu.cn (Yang Sui) \\ ${ }^{*}$ Corresponding author
}

\section{To cite this article:}

Rui Ding, Jintao Xu, Yang Sui. An Integrated Management System for Quality, Health and Safety, and Environment: A Case Study. Journal of Electrical and Electronic Engineering. Vol. 9, No. 5, 2021, pp. 170-179. doi: 10.11648/j.jeee.20210905.14

Received: September 10, 2021; Accepted: October 18, 2021; Published: October 30, 2021

\begin{abstract}
The nuclear power plant (NPP) project (NPPP) usually faces with the complex quality, health and safety, and environment (QHSE) risks, so that it is vital to establish the QMS, OHSMS, and EMS, as is called QHSEMSs, according to ISO 9001, ISO 45001, and ISO 14001 standards, as is called the three ISO standards, respectively. Meanwhile, the QHSEMSs need to be supplemented and improved according to IAEA safety standards due to its industry particularity, and the special QHSEMSs need to be established and then implemented. However, during establishing and implementing the special QHSEMSs for NPPP, problems including huge numbers of documents, complex organizational structures, cumbersome management processes, lower management efficiency, and higher management cost are encountered. In order to solve these problems, a generic model for integrating the special QHSEMSs into an integrated management system (IMS) for QHSE (QHSEIMS) for NPPP in China was proposed according to the three ISO standards and IAEA safety standards through PDCA, process, and system approaches, as is called the three integration approaches. The proposed model was applied to establish and implement the QHSEIMS in a typical case, and the application results indicated that the proposed model was of great help to streamline the documentation, organizational structure, and management process for QHSE, and to effectively and efficiently manage the QHSE for the NPPP.
\end{abstract}

Keywords: Nuclear Power Plant Project, Integrated Management System, QHSE, Integration Approaches, ISO Standards, IAEA Safety Standards

\section{Introduction}

The nuclear power plant (NPP) project (NPPP) usually faces with complex quality, health and safety, and environment (QHSE) risks $[1,2]$. Therefore, it is vital to establish the quality management system (QMS), occupational health and safety management system (OHSMS), and environmental management system (EMS), as is called QHSE management systems (MSs) (QHSEMSs), according to International Organization for Standardization (ISO) 9001, ISO 45001, and ISO 14001 standards, as is called the three ISO standards, separately for NPPP [3, 4]. Meanwhile, due to its industry particularity, the QHSEMSs need to be supplemented and improved according to International Atomic Energy Agency (IAEA) safety standards, and the special QHSEMSs need to be established and then implemented to manage the QHSE [5, 6].

However, during establishing and implementing the special QHSEMSs for NPPP the following problems are encountered [7-9].

1) Three sets of system documents should be established to regulate the QHSE management, resulting in huge numbers of documents;

2) Three organizational structures should be set up to operate and maintain the QHSEMSs, causing the complex organizational structures;

3) Three management processes should be built up to control the processes for QHSE, making the cumbersome management processes and lower management efficiency; 
4) Three kinds of manpower, material and financial resources should be allocated, leading to the higher management cost.

Previous studies have shown that those problems can be solved by establishing a model for integrating the QHSEMSs into an integrated management system (IMS) for QHSE (QHSEIMS) [10]. This model can be used to establish and implement the QHSEIMS so as to streamline the documentation, organizational structure, and management process for QHSE, to reduce the management cost, and to enhance the management efficiency [11, 12]. Some researchers have proposed specific models for establishing and implementing the QHSEIMS for road, railway, port, building, hospital, and hydroelectricity projects [13, 14]. However, there have been no study on how to propose such a model for NPPP.

Therefore, this paper aims to propose a generic model for establishing and implementing the QHSEIMS for NPPP in China according to the three ISO standards and IAEA safety standards through Plan-Do-Check-Action (PDCA), process, and system approaches, as is called the three integration approaches, and to apply this model to a typical case in East China.

The structure of this article is as follows: the first part is introduction, in which the authors describe the research objectives of this paper; the second part introduces the literature review and background; the materials and method is presented in the third part; the fourth part proposes a generic model; the proposed model is applied in a typical case in the fifth part; and in the sixth, the authors give the conclusions.

\section{Literature Review and Background}

\subsection{International Standards on QHSE Management}

\subsubsection{ISO 9001 Standard}

ISO is an independent and non-governmental international agency on standardization [15]. Its main work is to formulate international standards, to deal with the relevant standardization issues, and to coordinate the standardization work around the world. So far, ISO standards have become the ones that international organizations have to comply with when they establish the standardized systems [16].

In 2015, ISO issued the ISO 9001 standard (5th edition). As the general requirements for QMS, the standard provides a scientific method for quality management and quality assurance for international organizations and helps them to improve their product quality and service level [17].

Any organization can establish and implement the QMS according to ISO 9001 standard so as to standardize its quality activities, to strengthen the quality process control, to reduce the quality loss, to manage the influence factors on project quality, to minimize the quality risk, to produce or provide the high quality products or services meeting the stakeholders' expectations and requirements, to establish a good quality culture to improve quality performance, and to achieve the established quality objectives [18, 19].

\subsubsection{ISO 45001 Standard}

In March 2018, ISO issued the ISO 45001 standard (1st edition). Although the standard is a new one, it replaces the Occupational Health and Safety Assessment Series (OHSAS) 18001 standard issued by British Standards Institution (BSI), and its foundation is strong enough [20]. Currently, all the international organizations which have passed the OHSAS 18001 certifications have three years of transition time for recertification, that is, they should accomplish the certification transition from OHSAS 18001 certification to ISO 45001 certification before March 2021 so as to meet the requirements of ISO 45001 standard [21].

Any organization can establish and implement the OHSMS according to ISO 45001 standard or BSI 18001 standard so as to standardize its occupational health and safety (OHS) activities, to identify the OHS hazards and to assess and control hazards-related risks, to prevent the OHS accidents or effectively control the consequences of OHS accidents, to establish a good safety culture to improve OHS performance, and to achieve the established OHS objectives [22].

\subsubsection{ISO 14001 Standard}

In 2015, ISO issued the ISO 14001 standard (3rd edition). As the widely accepted international environmental standard, it provides a scientific method for environmental management for international organizations and helps them to improve the environmental management level [23].

Any organization can establish and implement the EMS according to ISO 14001 standard so as to standardize its environmental activities, to reduce or control the generation, and discharge or waste from pollutants or wastes, to find out the potential environmental problems and to eliminate or reduce the negative effects on the environment, to minimize the environmental risk, to establish a good environmental culture to improve environmental performance, and to achieve the established environmental objectives [24, 25].

\subsubsection{IAEA Safety Standards}

IAEA is a scientific and technological cooperation organization in the field of international atomic energy between governments [26]. Its main work is to formulate the international nuclear safety standards, to deal with the nuclear safety issues, and to promote the nuclear safety worldwide [27]. So far, IAEA safety standards have become the foundation stone of international nuclear safety system [28].

IAEA has issued lots of safety standards. These standards require that the member states should establish a sustainable management system for their nuclear facilities and comprehensively take into account the QHSE so as to ensure the coordination, unity and effectiveness of QHSE management in member states [29].

In China, the relevant national standards, which are identical to the three ISO standards and IAEA safety standards, are published [30]. 


\subsection{Integration Approaches for QHSEMSS}

Currently, the three integration approaches are usually used to establish and implement a QHSEIMS or to establish its model for the above mentioned industrial projects [31].

\subsubsection{PDCA Approach}

PDCA approach, also called PDCA cycle or Deming cycle, is a scientific one used to guide the quality management for an organization. It divides the quality activities into Plan, Do, Check, and Action four stages so that they can be conducted in a clear and systematic process to promote the continuous improvement on quality [32].

All the new international standards on MSs by ISO have a uniform High Level Structure (HLS), and they have the identical structures and chapters. These chapters align with the four phases in PDCA approach [33].

Jørgensen et al. [34] believed that an IMS for QHSE and corporate social responsibility (CSR) should be established based on the policy and planning, implementation, corrective action, and management review, which constituted a PDCA process. Muzaimi et al. [35] used the PDCA approach to implement the QHSEIMS including setting the milestone to be achieved at the Plan stage, providing training, inspecting the QHSE, reviewing and completing the QHSEMSs, and defining the processes at the Do stage, slightly adjusting the QHSEMSs through a difference analysis at the Check stage, and determining the future improvement at the Action stage.

\subsubsection{Process Approach}

Process approach is a scientific one which studies and deals with the used processes for an organization. It is used to determine the objectives for an organization, and to systematically identify and manage the interrelated and functional processes in the process of achieving the objectives [36].

Sanorlam and Thawesaengskulthai [37] considered that all the MSs can be integrated through process approach so as to streamline the process and improve the system effectiveness. Ahidar et al. [38] used the process approach to establish a practical framework in which the implementation of IMS was divided into a series of continuous processes and each process contained continuous activities. Asif et al. [39] designed an IMS for QHSE and CSR implementation through process approach which contained 3 successive stages including designing core processes, improving process performance, and integrating strategy and operations In the first stage, each activity was designed from the stakeholders' requirements and expectations. In the second stage, all the processes were managed effectively and efficiently. In the third stage, the improved processes (through the above two stages) were embedded into the mainstream of QHSEMSs.

\subsubsection{System Approach}

System approach is a scientific one which studies and deals with the problem in a system by system thinking. It regards the research object as a single system, analyzes the composition and function of the system, investigates the interactive relationships among the elements in the system, and finds the best way to deal with the problem and optimizes the system by system analysis [40].

Pojasek [41] believed that the three ISO standards could be embedded into a QHSEIMS through system approach, employee focus, and process view. Rocha et al. [42] built an IMS for QHSE and CSR containing 7 key elements through system approach, and incorporated the sustainability in line with mainstream business infrastructure into it.

\subsection{Models for QHSEIMS}

A model for the QHSEIMS can help an organization to integrate the QHSEMSs, to promote the sustainable development, to improve the management performance, to support the development of the QHSEIMS [43], and most importantly, such model can provide the guidelines and practical recommendations on the QHSEIMS within the industry [44]. Therefore, many investigators have tried to establish the models for the QHSEIMS through the above described three integration approaches.

Bernardo [45] proposed a model to study the connection between the IMS and innovation management performance. Dale [46] established a model for the QHSEIMS which showed what the organizations needed to consider in implementing the QHSEIMS. Rößler and Schlieter [47] presented the design proposals for proposing a model-based method to integrate the MSs and provided methodological support for implementing an IMS for QHSE and emergency in practice. Tarí and Molina-Azorín [48] proposed a model which was used as the foundation for integrating the QMS and EMS. Zeng et al. [49] proposed a 3-level synergy model for implementing a QHSEIMS for an empirical research project. Olaru et al. [50] made a comparison study on various models for the QHSEIMS.

Rofi'udin and Latief [51] put forward a conceptual model for the QHSEIMS by PDCA approach which included the policy of leadership system at the Plan stage, supporting processes and operations at the Do stage, audit and management review at the Check stage, and continuous improvement at the Action stage. Rebelo et al. [52] proposed a model for the QHSEIMS containing seven components based on PDCA approach. Hamid et al. [53] suggested a model for the QHSEIMS containing six components by PDCA approach.

Badreddine et al. [54] believed that the process approach can be used to model all the processes for an organization and put the interaction between them into the same model. El Idrissi et al. [55] applied the process approach to propose a conceptual process model for the QHSEIMS consisting of three main dimensions, which were function dimension including leadership, politics/strategy, and communication, tactical issue dimension containing planning, implementation, measures, analysis, and improvement, and strategic dimension containing labour, matter, equipment, environment, and method. 
Jurčević [56] proposed a system model for an IMS using the system approach in which QHSEMSs and CSR and financial MSs were considered as parts of a system and analyzed so as to satisfy the requirements and expectations from stakeholders. Karapetrovic and Jonker [57] used the system approach to propose a system model for the IMS for QHSE and CSR which included determining the objectives, planning and designing the system, acquiring and deploying resources, operating the system, and evaluating and improving the system. Algheriani et al. [58] used a system model to implement the QHSEIMS through the QHSE objectives, processes, and resource management.

All these studies show that it is necessary to use a model compatible with the integration approaches for harmonizing, aligning, and finally integrating the QHSEMSs. However, there is no suitable model for the QHSEIMS for all organizations because the model is dependent on the characteristics and culture of the organizations [59].

The above literature review demonstrates that the QHSEIMS or its model for other industrial projects was proposed according to the three ISO standards through PDCA, or process, and or system approaches. However, there has not been a model for establishing and implementing the QHSEIMS for NPPP; and it is hard to judge which integration approach is more suitable to be used for proposing such a model because each integration approach has its own characteristics. In addition, the QHSEMSs for NPPP are required to take into account the IAEA safety standards, but there has not been such reference on how to do it.

Therefore, a generic model for establishing and implementing the QHSEIMS for NPPP should be proposed through the three integration approaches according to the three ISO standards and IAEA safety standards. In addition, the proposed model should be applied to establish and implement the QHSEIMS in a typical case so as to verify whether it can manage the QHSE effectively and efficiently.

\section{Materials and Method}

The questionnaire method has widely been used to establish and implement the QHSEIMS [60]. So, this method was used to propose a generic model for establishing and implementing the QHSEIMS for NPPP in China.

For the sake of the effectiveness of research, the authors consulted a large amount of literature on QHSEIMS and a great deal of information and data on QHSE management for NPPP in China, made face-to-face interviews with management representatives and employee representatives, and conducted on-site investigation in each NPP. Based on the work, a preliminary questionnaire was designed, the questionnaire was then corrected according to the advice from the experts in universities, and the formal questionnaire was defined. The formal questionnaire includes the following four items: 1) contents for establishing the QHSEIMS for NPPP according to the three ISO standards and IAEA safety standards; 2) processes for establishing and implementing the QHSEIMS for NPPP through PDCA approach; 3) processes for establishing and implementing the QHSEIMS for NPPP through process approach; and 4) processes for establishing and implementing the QHSEIMS for NPPP through system approach.

From January to March 2019, the questionnaires were distributed to the relative personnel including leader layers, managers, internal auditors, employees, and on-site workers through the information systems for all the NPPPs in China. The authors distributed 600 questionnaires, received 557 questionnaires, and kept 494 effective questionnaires, which showed that the effective rate was $88.9 \%$.

Finally, all the effective questionnaires were studied, the information and data were summarized and statistically analyzed, and the research contents in questionnaires were ascertained.

\section{Proposed Generic Model}

The processes for establishing and implementing the QHSEIMS for NPPP were determined through the three integration approaches, which were shown in Table 1.

Table 1. The processes for establishing and implementing the QHSEIMS for NPPP through the three integration approaches.

\begin{tabular}{|c|c|c|}
\hline No. & Approach & Processes \\
\hline 1 & $\begin{array}{l}\text { PDCA } \\
\text { approach }\end{array}$ & $\begin{array}{l}\text { 1) Determining the QHSE policy, allocating the necessary resources, and establishing the organizational structure at the Plan stage; } \\
\text { 2) Implementing the QHSEIMS, and organizing and carrying out the activities at the Do stage; } \\
\text { 3) Checking the system implementation, and evaluating the effectiveness of the system through the effective monitoring and } \\
\text { measurement at the Check stage; } \\
\text { 4) Formulating measures to continuously improve the system at the Action stage. }\end{array}$ \\
\hline 2 & $\begin{array}{l}\text { Process } \\
\text { approach }\end{array}$ & $\begin{array}{l}\text { 1) Analyzing the requirements and expectations from stakeholders, and determining the QHSE objectives; } \\
\text { 2) Systematically identifying all processes and relevant activities during implementing the QHSEIMS; } \\
\text { 3) Making clear the orders and interactive relationships among the processes and relevant activities; } \\
\text { 4) Improving and optimizing each process and relevant activities timely. }\end{array}$ \\
\hline 3 & $\begin{array}{l}\text { System } \\
\text { approach }\end{array}$ & $\begin{array}{l}\text { 1) Taking the QHSE management as a system; } \\
\text { 2) Systematically designing the elements, objectives, processes, and resources for the QHSEIMS; } \\
\text { 3) Based on the results of step 2, designing and implementing the plan for establishing and implementing the QHSEIMS; } \\
\text { 4) Systematically analyzing the information and data related to the QHSEIMS so as to optimize the system functions. }\end{array}$ \\
\hline
\end{tabular}

Based on the determined processes in Table 1, a generic model for establishing and implementing the QHSEIMS for NPPP in China was proposed, which was shown in Figure 1. 


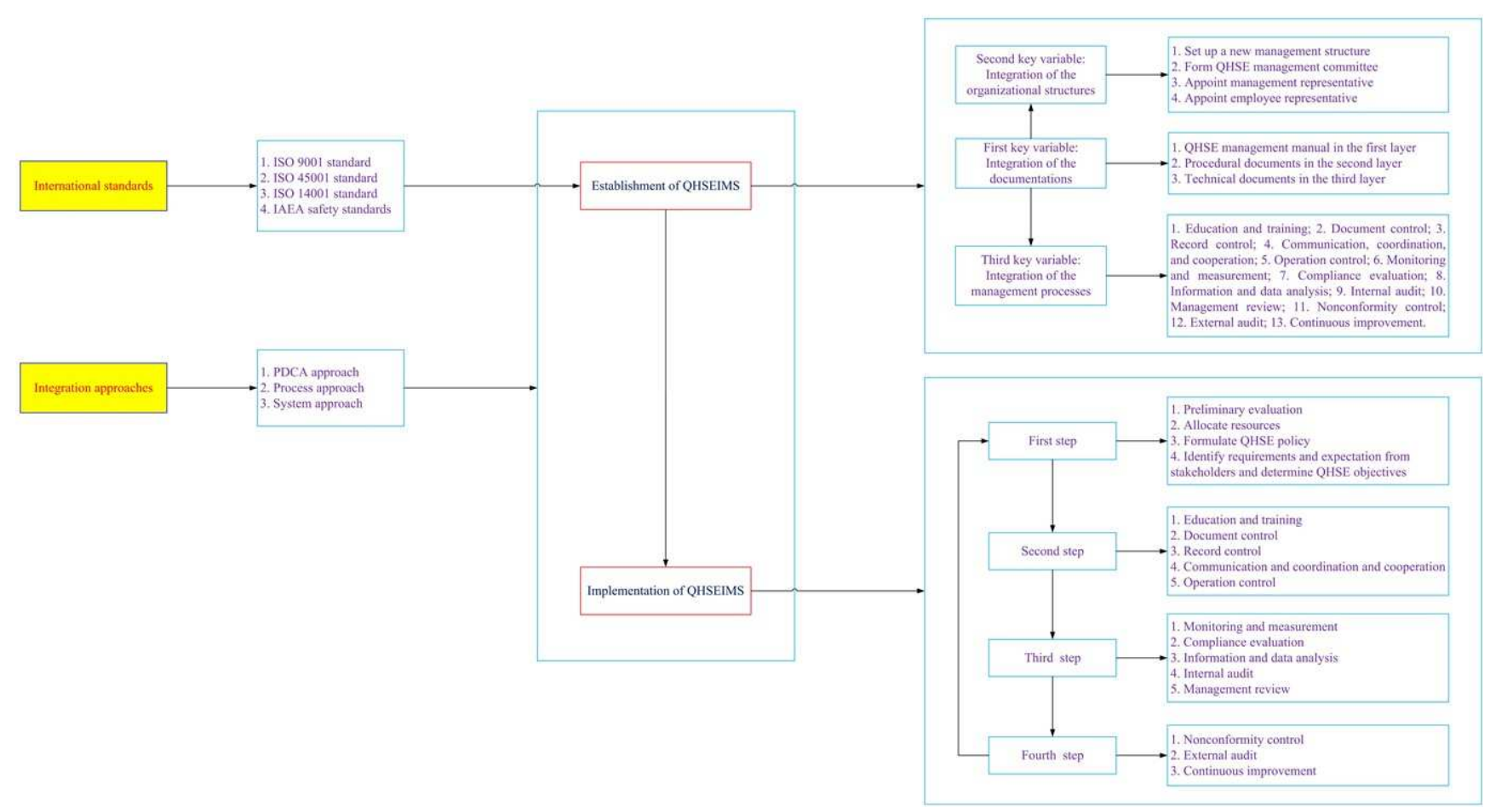

Figure 1. A generic model for establishing and implementing the QHSEIMS for NPPP in China.

\section{Model Application}

\subsection{Typical Case}

In this section, the model was applied to establish and implement the QHSEIMS for the NPPP in Fujian Fuqing Nuclear Power Corporation Limited (FQNP). Units 1-4 in FQNP have been under operation. Units 5-6 have been under construction since May 2016, and they constitute the NPPP. The construction of Units 1-4 has provided valuable experience for that of Units 5-6.

During the NPP under construction, it is hard to ensure the project quality and protect the workers' OHS and environment because the QHSE risks are very high due to many participating teams, complex organizational structures and management processes, and dynamic working environment. Consequently, it is vital to establish and implement a QHSEIMS so as to effectively and efficiently manage the QHSE, and to ensure the project quality and protect the workers' OHS and environment while the NPP is under construction.

\subsection{Establishment of QHSEIMS}

The QHSEIMS for the NPPP in FQNP was established in terms of three key variables including the integrations of the documentations, the organizational structures, and the management processes according to the three ISO standards and IAEA safety standards.

\subsubsection{Integration of the Documentations}

The integration of the documentations included QHSE management manual in the first layer, procedural documents in the second layer, and technical documents in the third layer.

(i) QHSE management manual

The three ISO standards have a uniform HLS and common elements, and this creates favorable conditions for establishing the QHSEIMS. The elements of QHSE management manual were established according to common elements, and the QHSE management manual was then established according to the general requirements of the three ISO standards and IAEA safety standards.

The QHSE management manual is the programmatic document for QHSEIMS, which puts forward the principles on the integration management on QHSE, and is the standard and principle of conducting the QHSE activities.

(ii) Procedural documents

The procedural documents were established to further satisfy the requirements of the three ISO standards and IAEA safety standards.

The procedural documents, which are the expansion of QHSE management manual, stipulate the specific methods and ways to achieve the QHSE objectives, and describe the responsibilities, measures, resources and activities for the integration management on QHSE in detail.

(iii) Technical documents

The technical documents including operating procedures, working plans, detailed working codes, construction drawings, records (forms, images, and reports), etc, which are the supporting documents and detailed rules of procedural documents, are the management methods or operation schemes for specific matters. They clarify the achieved results or provide the evidence for activities.

\subsubsection{Integration of the Organizational Structures}

Based on the basis of the integration of the documentations, 
the organizational structures were integrated from setting up a new management structure, forming QHSE management committee, appointing management representative, and appointing employee representative.

(i) Setting up a new management structure
A new management structure was set up to define the responsibilities and authorities on QHSE management for leader layer, departments, working groups, and personnel. The new QHSE management structure for the NPPP in FQNP was shown in Figure 2.

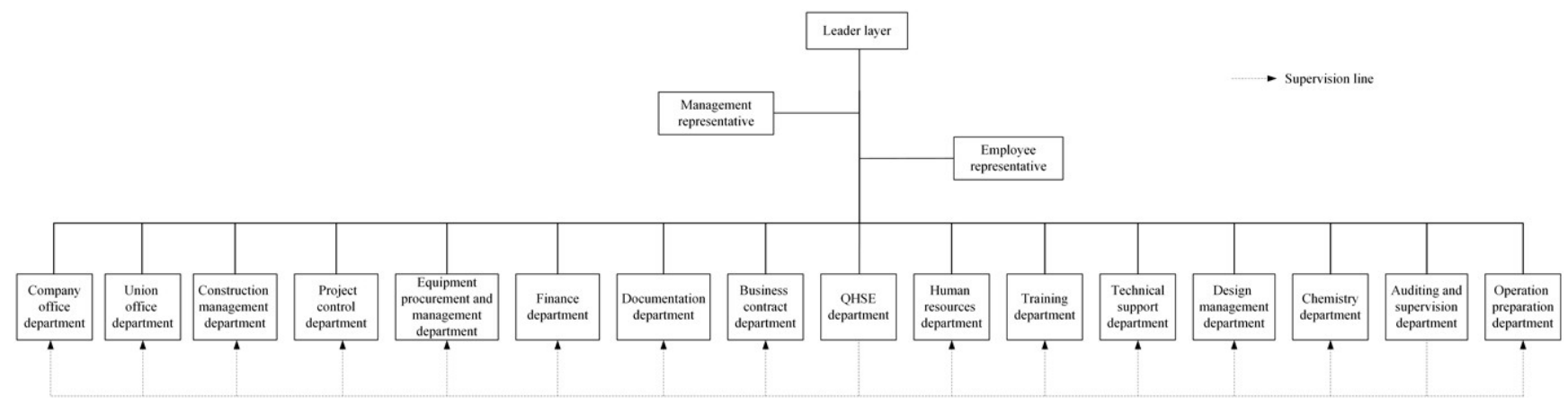

Figure 2. QHSE management structure for the NPPP in FQNP.

(ii) Forming QHSE management committee

The QHSE management committee was formed. Its main responsibilities were as follows: 1) guiding the establishment and implementation of QHSEIMS; 2) arranging the QHSE activities; 3) discussing and deciding the major QHSE matters; 4) reviewing resource allocation and providing enough resources; and 5) coordinating and solving the problems in the integration management on QHSE.

(iii) Appointing management representative

The deputy general manager in charge of QHSE management was appointed as the management representative His main responsibilities included: 1) organizing the establishment and implementation of QHSEIMS; 2) presiding over the internal audit meeting; 3) reporting the demand for improving the QHSEIMS performance to the top leader regularly; and 4) taking charge of external communication and liaison on QHSE matters.

(iv) Appointing employee representative

The chairman was appointed as the employee representative. His main responsibilities included: 1) protecting the employees' legitimate rights and interests; and 2) reflecting the opinions and suggestions from employees on QHSE to the leader layer.

\subsubsection{Integration of the Management Processes}

During the establishment and implementation of QHSEMSs, three management processes need to be established, and each one includes: 1) education and training; 2) document control; 3) record control; 4) communication, coordination, and cooperation; 5) operation control; 6) monitoring and measurement; 7) compliance evaluation; 8) information and data analysis; 9) internal audit; 10) management review; 11) nonconformity control; 12) external audit; and 13) continuous improvement. On the basis of the integration of the documentations, the three management processes were integrated into one management process for QHSE.

\subsection{Implementation of QHSEIMS}

The QHSEIMS for the NPPP in FQNP was implemented in the following four steps.

\subsubsection{First Step}

In the first step, the main work included preliminary evaluation, allocating resources, formulating QHSE policy, and identifying requirements and expectation from stakeholders and determining QHSE objectives.

(i) Preliminary evaluation

The preliminary evaluation was to investigate and analyze the status and understand the QHSE management conditions.

(ii) Allocating resource

The demand plan for allocating resource was formulated by identifying the QHSE activities based on the principles of safety, availability and efficiency, and its implementation was inspected and audited so as to adjust and optimize the resources timely.

(iii) Formulating QHSE policy

The following QHSE policy was to describe the purpose and behavior principle of the integration management on QHSE, and it was formulated by the top leader of the FQNP: 1) safe production and people orientation; 2) prevention first and elimination of potential hazards; 3) prudence and rigorousness and well execution; and 4) continuous improvement and pursuit of excellence.

(iv) Identifying the requirements and expectation from stakeholders and determining the QHSE objectives

The requirements and expectations from stakeholders including society, shareholders, customers, suppliers, employees, and local community, etc were identified regularly, the relevant information was collected, and the feasible QHSE objectives were determined. The fulfillment of the QHSE objectives was monitored and audited effectively so as to satisfy the requirements and expectations from stakeholders.

\subsubsection{Second Step}

In the second step, the main work included education and training, document control, record control, communication and coordination and cooperation, and operation control. 
(i) Education and training

FQNP educated and trained all its personnel. The training mainly included the three ISO standards and IAEA safety standards, and QHSEIMS. Through the education and training, all personnel could have a clear and comprehensive understanding of the integration management on QHSE.

(ii) Document control

FQNP controlled the compilation, review, approval, release, distribution, revision, cancellation, retention, and storage of the documents so that the personnel could obtain the latest version of documents timely.

(iii) Record control

FQNP controlled the generation, collection, cataloguing, identification, distribution, classification, inspection, volume, processing, storage, and keeping of the records so as to provide the evidence that could meet the requirements of the three ISO standards and IAEA safety standards, stakeholders, and integration management on QHSE.

(iv) Communication, coordination, and cooperation

FQNP established the mechanism for internal and external communication, coordination, and cooperation, and defined the channels and methods for communication, coordination, and cooperation for the QHSE affairs, especially the control of major QHSE risks, so as to ensure the timely and effective exchange of information on QHSE.

(v) Operation control

FQNP made the overall plan for QHSE activities on the premise of meeting the feasibility and effectiveness, and controlled these activities. It mainly carried out the operation control from the following five aspects: 1) design and development of NPP products and services; 2) governance of products, services, and processes which were provided by external organization; 3) release of NPP products and services; 4) QHSE hazards identification and risk assessment and treatment; and 5) emergency preparedness and response.

\subsubsection{Third Step}

In the third step, the main work included monitoring and measurement, compliance evaluation, information and data analysis, internal audit, and management review.

(i) Monitoring and measurement

FQNP monitored and measured the satisfaction degree of requirements and expectations from stakeholders, the completion degree of objectives and indicators, the implementation processes of the QHSEIMS, and the characteristics of products. It collected and kept all the above information and data.

(ii) Compliance evaluation

FQNP regularly identified and analyzed the suitability of the three ISO standards and IAEA safety standards, and evaluated the compliance of the QHSEIMS with the standards so as to fulfill the commitment to complying with them.

(iii) Information and data analysis

FQNP regularly analyzed all the information and data related to the QHSEIMS, and determined the development trend of the integration management on QHSE so as to provide the basis for formulating the corrective and preventive measures and improving the system performance.

(iv) Internal audit

FQNP formulated the internal audit plan every year, and carried out the internal audit in accordance with the plan so as to make sure that the QHSEIMS meets the requirements of the three ISO standards and IAEA safety standards to verify the conformance of QHSE activities with the QHSEIMS, and to provide references for management review, external audit and continuous improvement.

(v) Management review

FQNP carried out the management review every year, and examined the corrective and preventive measures for the nonconformity in internal audits to comprehensively evaluate the effectiveness of QHSEIMS, to discuss and approve the important corrective and preventive measures, and to clarify the next step for the integration management on QHSE.

\subsubsection{Fourth Step}

In the fourth step, the main work included nonconformity control, external audit, and continuous improvement.

(i) Nonconformity control

FQNP checked the nonconformity timely and took the corrective measures immediately to eliminate the nonconformity. It investigated the major nonconformity, analyzed its direct causes and root causes, and formulated and implemented the corrective and preventive measures to prevent the similar nonconformity.

(ii) External audit

The third-party certification organization conducted external audit every year. It reviewed and evaluated the compliance of the QHSEIMS with the three ISO standards through the seminar, document and record audit, and on-site investigation, and finally decided whether the company could pass the three ISO certifications simultaneously or not.

(iii) Continual improvement

FQNP regularly carried out the continual improvement actions including peer evaluation, external supervision, and experience feedback, etc to continuously improve the effectiveness of QHSEIMS.

\subsection{Results and Discussion}

In November 2019, the third-party certification organization conducted the annual external audit for the three ISO standards for the NPPP in FQNP. The external audit indicated that the QHSEIMS was effective and FQNP had the good conditions to pass the three ISO certifications simultaneously by the end of 2020 .

The organization also evaluated the integration degree of QHSEIMS in terms of the integrations of the documentations, the organizational structures, and the management processes for the NPPP. The evaluation results indicated that FQNP achieved the full integration of QHSEMSs and could effectively and efficiently manage the QHSE. Therefore, the model applicability was verified. 


\section{Conclusions}

In this research, a generic model for establishing and implementing the QHSEIMS for NPPP in China was proposed according to the three ISO standards and IAEA safety standards through the three integration approaches. The generic model was applied to a typical case in East China, and to help it to establish and implement the QHSEIMS. The results indicated that the QHSE risk level was well for the ONPP in FQNP. The establishment of QHSEIMS included the integrations of the documentations, the organizational structures, and the management processes, and the implementation of QHSEIMS was elaborated in detail in four steps. The results showed that the proposed model was of great help to streamline the documentation, organizational structure, and management process for QHSE, to effectively and efficiently manage the QHSE, to reduce the QHSE risks as low as reasonably achievable, and to achieve a high quality, healthy and safe working condition, and clear environment for the NPPP.

The contributions of this research lie in: 1) the literature review was increased on the QHSEIMS for NPPP; 2) a generic model for establishing and implementing the QHSEIMS for NPPP was first proposed; and 3) the proposed model was of great help to establish and implement a QHSEIMS and effectively and efficiently manage the QHSE for NPPP.

But, the limitation of this paper is that the model is only applied to a typical case. Thus, in further studies, we will: 1) apply the model to all the other NPPPs and guide them to establish and implement their QHSEIMSs; and 2) assess the effectiveness of the established QHSEIMS.

\section{Acknowledgements}

This paper is supported by the National Natural Science Foundation of China (Grant No. 11805094 and No. 52174189).

\section{References}

[1] Sui, Y., Ding, R., Wang, H., 2020. A novel approach for occupational health and safety and environment risk assessment for nuclear power plant construction project. J. Clean. Prod. 258, 120945.

[2] Shin, D. W., Shin, Y., Kim, G. H., 2016. Comparison of risk assessment for a nuclear power plant construction project based on analytic hierarchy process and fuzzy analytic hierarchy process. J. Building Construct. Planning Res. 4 (3), 157-171.

[3] ISO, 2015. Quality management systems - Requirements. International Organization for Standardization, Switzerland.

[4] ISO, 2018. Occupational health and safety management systems - Requirements with guidance for use. International Organization for Standardization, Switzerland.

[5] IAEA, 2016. Leadership and Management for Safety. International Atomic Energy Agency, Vienna.

[6] IAEA, 2015. Preparedness and Response for a Nuclear or Radiological Emergency. International Atomic Energy Agency, Vienna.
[7] Domingues, J. P. T., Sampaio, P., Arezes, P., 2012. New organizational issues and macroergonomics: integrating management systems. Int. J. Hum. Factors Ergon. 1 (4), 351-375.

[8] Oliveira, O. J., 2013. Guidelines for the integration of certifiable management systems in industrial companies. J. Clean. Prod. 57, 124-133.

[9] Sampaio, P., Saraiva, P., Domingues, P., 2012. Management systems: integration or addition? Int. J. Qual. Reliab. Manag. 29, 402-424.

[10] Rebelo, M. F., Santos, G., Silva, R., 2014a. A generic model for integration of quality, environment and safety management systems. TQM J. 26 (2), 143-159.

[11] Bernardo, M., Alexandra, S., Tarí, J. J., Molina-Azorín, J. F., 2015. Benefits of management systems integration: a literature review. J. Clean. Prod. 94, 260-267.

[12] Domingues, J. P. T., Sampaio, P., Arezes, P. M., 2017. Management systems integration: survey results. Int. J. Qual. Reliab. Manag. 34, 1252-1294.

[13] Tepaskoualos, F, Chountalas, P., 2017. Implementing an integrated health, safety and environmental management system: the case of a construction company. Int. J. Qual. Res. 11 (4), 733-752.

[14] Zeng, S. X., Chun, M. T., Tam, V. W. Y., 2010. Integrating safety, environmental and quality risks for project management using a FMEA method. Inzinerine Ekonomika-Eng. Econ. 21 (1), 44-52.

[15] Thonhauser, T., Passmore, D., 2006. ISO 9000 in education: a comparison between the United States and England. Research in Comparative and International Education 1 (2), 156-173.

[16] Vrellas, C. G., Tsiotras, G., 2015. Quality management in the global brewing industry. Int. J. Qual. Reliab. Manag. 32, 42-52.

[17] İlkay, M. S., Aslan, E., 2012. The effect of the ISO 9001 quality management system on the performance of SMEs. Int. J. Qual. Reliab. Manag. 29 (7), 753-778.

[18] Souza, J. P. E., Alves, J. M., 2018. Lean-integrated management system: a model for sustainability improvement. J. Clean. Prod. 172, 2667-2682.

[19] Pheng, L. S., Abeyegoonasekera, B., 2001. Integrating buildability in ISO 9000 quality management systems: case study of a condominium project. Build. Environ. 36 (3), 299-312.

[20] Ghahramani, A., Salminen, S., 2019. Evaluating effectiveness of OHSAS 18001 on safety performance in manufacturing companies in Iran. Saf. Sci. 112, 206-212.

[21] Yahya, R., Handayani, N. U., Purwanggono, B., 2018. Analysis of OHSAS 18001: 2007 standard renewal towards ISO 45001: 2018 at PT. Power Plant Indonesia by using gap analysis method. SHS Web Conf. 49, 01009.

[22] Morgado, L., Silva, F. J. G., Fonseca, L. M., 2019. Mapping occupational health and safety management systems in Portugal: outlook for ISO 45001: 2018 adoption. Procedia Manuf. 38, 755-764.

[23] Veltri, A., Kruse, T., Branscum, A., 2019. Integrating safety, health and environmental management systems: a conceptual framework for achieving lean enterprise outcomes. J. Safety Res. 71, 259-271. 
[24] Santos, G., Rebelo, M., Lopes, N., Alves, M. R., Silva, R., 2016. Implementing and certifying ISO 14001 in Portugal: motives, difficulties and benefits after ISO 9001 certification. Total Qual. Manag. Bus. Excell. 27 (11-12), 1211-1223.

[25] Oliveira, J. A., Oliveira, O. J., Ometto, A. R., Ferraudo, A. S., Salgado, M. H., 2016. Environmental management system ISO 14001 factors for promoting the adoption of cleaner production practices. J. Clean. Prod. 133, 1384-1394.

[26] Abdel-Wahab, M., Rosenblatt, E., Holmberg, O., Meghzifene, A., 2011. Safety in radiation oncology: the role of international initiatives by the International Atomic Energy Agency. J. Am. Coll. Radiol. 8, 789-794.

[27] IAEA, 2019. Updates. https://www.iaea.org/ (accessed 16 May 2019)

[28] Kim, R, Jung, S. J, Choi, Y. S., 2017. Introduction to the institutional strength in depth for nuclear safety and its implications. Transactions of the Korean Nuclear Society Spring Meeting, Jeiu, Korea.

[29] IAEA, 2008. The Management System for the Processing, Handling and Storage of Radioactive Waste. International Atomic Energy Agency, Vienna.

[30] Li, F., 2014. HTR-PM safety requirement and licensing experience. 7th International Topical Meeting on High Temperature Reactor Technology. Weihai, China.

[31] Luo, H., Li, G., Li, C., 2015. Research on integration method of integrated management system. Open Autom. Contr. Syst. J. 1, 1802-1807.

[32] Deming, W. E., 2000. The New Economics for Industry, Government, and Education. MIT Press, Cambridge, MA.

[33] Nunhes, T. V., Bernardo, M., Oliveira, O J., 2019. Guiding principles of integrated management systems: towards unifying a starting point for researchers and practitioners. J. Clean. Prod. 210, 977-993.

[34] Jørgensen, T. H., Remmen, A., Mellado, M. D., 2006. Integrated management systems - three different levels of integration. J. Clean. Prod. 14, 713-722.

[35] Muzaimi, H., Chew, B. C., Hamid, S. R., 2017. Integrated management system: the integration of ISO 9001, ISO 14001, OHSAS 18001 and ISO 31000. AIP Conference Proceedings $1818,1-14$.

[36] Tkhakushinov, E. K., Zarubin, V. I., Nekrasova, S. O., Kuizheva, S. K., Ovsyannikova, T. A., 2015. Algorithm for organizing the process of ecological and economic system regulation of the territorial unit. Asian Soc. Sci. 11 (14), 297-305.

[37] Sanorlam, S., Thawesaengskulthai, N., 2017. Integrated quality safety and environmental management system for concrete roof manufacturer. 2017 4th International Conference on Industrial Engineering and Applications (ICIEA). IEEE, 255-259.

[38] Ahidar, I., Sarsri, D., Sefiani, N., 2019. Approach to integrating management systems: path to excellence application for the automotive sector using SYSML language. TQM J. 31 (2), 183-204.

[39] Asif, M., Bruijn, E. J., Fisscher, O. A. M., Searcy, C., Steenhuis, H.-J., 2009. Process embedded design of integrated management systems. Int. J. Qual. Reliab. Manag. 26, 261-282.

[40] Vasilkov, Y., Gushina, L., 2014. Analysis of the effectiveness and efficiency of management systems based on system analysis methodology. Int. J. Qual. Res. 8 (3), 347-356.
[41] Pojasek, R., 2006. Is your integrated management system really integrated? Environmental Quality Management 16 (2), 89-97.

[42] Rocha, M., Searcy, C., Karapetrovic, S., 2007. Integrating sustainable development into existing management systems. Total Qual. Manag. Bus. Excel. 18, 83-92.

[43] Rebelo, M. F., Santos, G., Silva, R., 2016. Integration of management systems: towards a sustained success and development of organizations. J. Clean. Prod. 127, 96-111.

[44] López-Fresno, P., 2010. Implementation of an integrated management system in an airline: a case study. TQM J. 22, 629-647.

[45] Bernardo, M., 2014. Integration of management systems as an innovation: a proposal for a new model. J. Clean. Prod. 82, $132-142$.

[46] Dale, B. G., 2007. Managing Quality. Blackwell Publishing, Oxford.

[47] Rößler, R., Schlieter, H., 2015. Towards model-based integration of management systems. In: Proceedings of the 12th International Conference on Wirtschaftsinformatik. Osnabrück, Germany, pp. 31-45.

[48] Tarí, J. J., Molina-Azorín, J. F., 2010. Integration of quality management and environmental management systems. Similarities and the role of the EFQM model. TQM J. 22 (6), 687-701.

[49] Zeng, S. X., Shi, J. J., Lou, G. X., 2007. A synergetic model for implementing an integrated management system: an empirical study in China. J. Clean. Prod. 15, 1760-1767.

[50] Olaru, M., Maier, D., Nicoară, D., Maier, A., 2014. Establishing the basis for development of an organization by adopting the integrated management systems: comparative studies of various models and concepts of integration. Procedia Soc. Behav. Sci. 109, 693-697.

[51] Rofi'udin, M., Latief Y., 2018. Integration process models of quality, safety, health and evironmental management systems to achieve sustainability construction. 8th International Conference on Industrial Engineering and Operations Management, IEOM 2018. Bandung, Indonesia, pp. 812-823.

[52] Rebelo, M. F., Santos, G., Silva, R., 2014b. Conception of a flexible integrator and lean model for integrated management systems. Total Qual. Manag. Bus. Excel. 25, 683-701.

[53] Hamid, A. R. A., Singh, B., Yusof, W. Z. W., Yang, A. K. T., 2004. Integration of safety, health, environment and quality (SHEQ) management system in construction: a review. Malays. J. Civ. Eng. 16 (1), 24-37.

[54] Badreddine, A., Romdhane, T. B., Amor, N. B., 2009. A new process-based approach for implementing an integrated management system: quality, security, environment. In: Proceedings of the International Multi Conference of Engineers and Computer Scientists. IMECS, Hong Kong, pp. 18-20.

[55] El Idrissi, H. E. Y., Bouami, D., Cherkaoui, A., 2014. Integrated management system: towards a new approach and a new model. Int. J. Serv. Oper. Manag. 19 (3), 338-359.

[56] Jurčević, M., 2019. The Analysis of the Process of Building an Integrated Management System. In: Darko, T., Domagoj, H. (Eds.), 7th International OFEL Conference on Governance, Management and Entrepreneurship: Embracing Diversity in Organisations. Dubrovnik, Croatia, pp. 381-390. 
[57] Karapetrovic, S., Jonker, J., 2003. Integration of standardized management systems: searching for a recipe and ingredients. TQM J. 14 (4), 451-459.

[58] Algheriani, N. M. S., Majstorovic, V. D., Kirin, S., Spasojevic Brkic, V., 2019. Risk model for integrated management system. Technical Gazette 26 (6), 1833-1840.

[59] Bernardo, M., Casadesus, M., Karapetrovic, S., Heras, I., 2009.
How integrated are environmental, quality and other standardized management systems? An empirical study. J. Clean. Prod. 17, 742-750.

[60] Carvalho, K. M. P., Picchi, F., Camarini, G., Chamon, E. M. Q. O., 2015. Benefits in the implementation of safety, health, environmental and quality integrated system. Int. J. Eng. Technol. 7 (4), 333-338. 